\title{
Patterns of uveitis among Nepalese population presenting at a tertiary referral eye care centre in Nepal
}

\author{
Ranju Kharel (Sitaula) ${ }^{1}$, Anadi Khatri ${ }^{2 *}$, Nita Sunam Gamal ${ }^{3}$, Ananda Kumar Sharma ${ }^{1}$ and Dev Narayan Shah ${ }^{1}$ \\ ${ }^{1}$ Department of Ophthalmology, BP Koirala Lions Centre for Ophthalmic Studies, Maharajgunj Medical Campus, Tribhuvan University, Institute of Medicine, \\ Kathmandu, Nepal \\ ${ }^{2}$ Birat Eye Hospital,Biratnagar,Nepal \\ ${ }^{3}$ Lamahi Eye Hospital, Dang, Nepal
}

\begin{abstract}
Purpose: To report the epidemiological profile, clinical pattern, and etiology of uveitis among large population of uveitis cases at a tertiary level eye care center of Nepal.

Methods: A retro-prospective study was performed among the patients visiting the uveitis clinic of BP Koirala Lions Centre for Ophthalmic Studies from 20122017. Retrospective data was collected for June 2012 and June 2013 and prospective data were collected for July 2013- July 2017.

Results: During the period of 2012-2017, a total of 5,34,292 patients were examined at BP Koirala Lions Centre for Ophthalmic Studies out of which, 4359 patients were diagnosed as uveitis patients making a prevalence rate of $0.82 \%$. The incidence rate was at $0.14 \%$ ( 477 new cases every year). Out of them, 2342 (53.73\%) were female and 2017 (46.27\%) were male. The mean age of presentation was $37.91 \pm 17.2$ years with age range of 38 days to 84 years. Unilateral presentation (2905, $66.64 \%)$ was common than bilateral $(1454,33.36 \%)$. According to anatomical types, anterior uveitis was the most common $(2694,61.8 \%)$ followed by intermediate uveitis $(665,15.26 \%)$, posterior uveitis $(454,10.42 \%)$ and panuveitis $(546,12.53 \%)$. A specific diagnosis was established in $1602(36.75 \%)$ patients. The three most common infectious diseases were herpetic anterior uveitis $(608,13.95 \%)$, toxoplasmosis $(272,6.24 \%)$ and tuberculosis $(101,2.32 \%)$ whereas metabolic disorder $(177$, $4.06 \%)$, rheumatoid arthritis related uveitis $(62,1.42 \%)$ and sarcoidosis $(53,1.22 \%)$ were common systemic diseases identified. Macular edema was the most common complication (863 eyes, $14.85 \%)$.
\end{abstract}

Conclusion: Anterior uveitis is the most common form of manifestations. Unilateral presentation is prevalent than bilateral. Uveitis is mainly common among Nepalese people of productive age group of either gender. Seasonal Hyperacute panuveitis is the commonest cause of pediatric panuveitis.

\section{Introduction}

Uveitis is estimated to be responsible for $10 \%$ to $15 \%$ of total blindness and is responsible for 30,000 new cases of legal blindness each year [1,2]. Uveitis may occur in any age group, but most commonly affects those aged between 20 and 44 years [2-4]. Thus, uveitis is a common sight-threatening disease affecting the working age group with a significant socioeconomic impact. Various factors may influence these statistics, including age, gender, ethnicity, endemic infectious disease and genetic background within a specific area. Uveitis and scleritis are often associated with systemic diseases and can be vision threatening, with uveitis accounting for $2.8-10 \%$ of all cases of blindness, and scleritis leading to ocular complications in $29.4-84.6 \%$ of patients [5].

For uveitis, the regional distribution of various infectious pathogens, identification of new uveitic entities and improvement of diagnostic techniques contribute to changes in global disease pattern [5]. The various etiological causes of uveitis include infection, autoimmunity, trauma, iatrogenic (operative trauma) and idiopathic. Despite the advances in diagnostic medicine, etiology of a large number of cases of uveitis remains elusive and is often due to the autoimmune cause. Systemic conditions such as tuberculosis, leprosy, rheumatoid arthritis, acquired immunodeficiency syndrome (AIDS), sarcoidosis, primary intraocular lymphoma, etc. may have uveitis as their initial presentation. The study shows that $26 \%$ of uveitis patient have a definite association with systemic disease and a relationship with a sub clinical systemic disorder could be presumed in 23\% [6]. Thus, a careful thorough history and systemic evaluation is an essential first step in elucidating the cause of uveitis.

In this current report, we aim to present an overview of the landscape of all the uveitis cases from BP Koirala Lions Centre for Ophthalmic Studies (BPKLCOS) database- the demographic features, clinical pattern, their etiologic causes, and systemic associations over a 5 -year period at the largest tertiary referral eye center in Nepal.

\section{Materials and methods}

We conducted a retro-prospective analysis of 4359 consecutive patients with newly diagnosed uveitis at the Uveitis clinic service of BP Koirala Lions Centre for Ophthalmic Studies which runs the department of ophthalmology of the largest referral hospital of Nepal named as Tribhuvan University Teaching Hospital. The study was named as

${ }^{\star}$ Correspondence to: Anadi Khatri, Vitreoretina Consultant, Birat Eye Hospital, Biratnagar, Nepal, E-mail: anadikc@gmail.com

Key words: scleritis, shapu, tuberculosis, uveitis

Received: August 26, 2019; Accepted: September 27, 2019; Published: October 03,2019 
BPKLCOS Uveitis Study (BUS) and BUS database was collected over a 5-year period, from 2012 to 2017 among 5,34,292 patients. The clinical records of all patients with uveitis seen at our clinic between June 2012 to June 2013 were analyzed retrospectively and records from July 2013 to July 2017 prospectively with International Classification of Diseases, 10th Revision, Clinical Modification (ICD-10-CM) relevant to uveitis. The study adhered to the tenets of the Declaration of Helsinki and obtained permission from the Institutional Review Board (IRB) of the Institute of Medicine. Data was collected using a Microsoft Excel spreadsheet SPSS IBM Version 20 was used for statistical analysis.

Patient information collected included demographic and clinical profile such as gender, age at presentation, laterality of occurrence, anatomic \& etiologic diagnosis, medical and surgical treatment modalities, visual prognosis, and ocular complications. Patients were classified according to the widely accepted classification of uveitis established by the International Uveitis Study Group (IUSG) and later affirmed by the Standardization of Uveitis Nomenclature (SUN) working group and OASIS [7-9].

All available medical records retrieved were rechecked for validity by at least 2 ophthalmologists. Regarding the nature of the disease, uveitis was divided into acute uveitis, defined as the sudden onset of intraocular inflammation lasting less than 3 months, and chronic uveitis, which referred to an inflammatory episode of insidious onset that lasted longer than 3 months.

All patients underwent careful history searches for specific ocular uveitis entities or systemic disease associations together with ocular examinations, including best-corrected visual acuity (BCVA), tonometry, slit-lamp biomicroscopy, and indirect ophthalmoscopy.

Laboratory investigations for uveitis were employed, depending on anatomic classification, uveitis frequency, and severity, whether there were signs of granulomatous inflammation, and clinical clues for associated systemic illness. An array of laboratory investigations, including complete blood count, erythrocyte sedimentation rate, random blood sugar, urine routine examination, anti-HIV antibody testing, hepatitis serological profiles, anti-nuclear antibody (ANA), rheumatoid factor, serum calcium, serum uric acid, Treponema pallidum hemagglutination test, chest radiography and Mantoux test were performed in all cases except patients with first attack of anterior uveitis, who respond well to topical corticosteroids. Other augmented tests were carried out in selected cases based on clinical suspicion. These tests included human leukocyte antigen (HLA)-B27 for ankylosing spondylitis, serum ACE for sarcoidosis, serum and vitreous toxoplasma antibodies for toxoplasmosis, quantiFERON TB gold test for suspected intraocular tuberculosis, fundus fluorescein angiography and optical coherence tomography. Since Indocyanine green angiography (ICG) was not available, it could not be performed, similarly, Polymerase Chain Reaction (PCR) was not performed due to unavailability. But aqueous and vitreous tap was done whenever it was necessary to perform cytology, staining and culture sensitivity tests.

The specific diagnosis was either confirmed or strongly suspected by the aforementioned meticulous examination and clinical history, extensive systematic reviews, ocular findings, and laboratory and ancillary tests. Medical consultation was done when indicated. Systemic diseases, such as sarcoidosis and Behçet disease were diagnosed according to current international diagnostic criteria [10,11].

Vogt-Koyanagi-Harada (VKH) disease was diagnosed by the diagnostic criteria suggested by Read et al [12]. Presumed tuberculous (TB) uveitis was diagnosed if active TB was present, or there was a positive tuberculin skin test or quantiFERON TB gold, or response to an empirical trial of anti-tuberculous treatment, in the absence of other possible causes.

The diagnosis of herpetic anterior uveitis was primarily based on suggestive clinical characteristics, for instance, positive history of herpetic infection, scarring in the corneal stroma, iris atrophy, decrement of corneal sensation or elevated intraocular pressure.

The diagnosis of ocular toxoplasmosis was based on the distinctive retinal findings, that is, focal necrotizing retinitis or retinochoroiditis, which may be associated with pigmented retinochoroidal scar in either eye. Vitreous IgG titer for toxoplasma Gondii was done doubtful cases.

Seasonal Hyperacute panuveitis (SHAPU) was defined as Unilateral red eye without discharge associated with significant vision impairment occurring soon after monsoon, with no prior history of surgery or trauma [13]. Hypopyon, fibrinous exudates in anterior chamber, a difficult to dilate pupil and inability to visualize retina because of massive exudation into vitreous producing a "White pupil in Red eye" with little or no pain are the other characteristic features of the disease [14].

Diagnosed cases of psoriasis, leprosy Behcet's, gout, idiopathic intracranial hypertension, small bowel gastrointestinal stromal tumor (GIST), and Langerhans Cell Histiocytosis and collagen vascular diseases were sent from the respected departments for ocular evaluation.

The cases for which diagnosis could not be determined were classified as idiopathic uveitis. Idiopathic uveitis was termed when no cause could be elicited for the intraocular inflammation. Consultations with pulmonologist, rheumatologist, a medical internist, dermatologist, venereologist and pediatrician were obtained as when required. The final etiological diagnosis was made based on clinical features, laboratory investigations, and systemic evaluation. All patients of endophthalmitis were excluded from the study.

A descriptive statistical analysis were reported as mean, medians, and standard deviation for continuous variables, and numbers (n) and percentages (\%) were used for categorical variables. Data were analyzed using SPSS 21.0 (SPSS Inc., Chicago, IL, USA). A p-value 0.05 was considered as statistically significant.

\section{Results}

This institutional-based retro-prospective study was conducted to analyze the pattern of uveitis patients at BP Koirala Lions Centre for Ophthalmic Studies, a tertiary referral eye care center of Nepal over five years period from June 2012 to July 2017. A total of 5,34,292 general patients were examined, out of which there were 4359 uveitis cases $(0.82 \%)$ were included in the study.

Among them, 2342 (53.73\%) were female and 2017 (46.27\%) were male. The demographic profile is shown in Table 1. The mean age of the patient was 37.91 years, the youngest being 38 days-old and the oldest being 84 years. Patients between 21-40 years of age constituted approximately $44 \%$ of the study group (Figure 1).

Unilateral presentation was more predominant than bilateral (66.64\% vs $33.36 \% \%)$. Anterior uveitis (AU) was the most common (2694, 61.8\%) followed by intermediate uveitis $(665,15.26 \%)$, posterior uveitis $(454,10.42 \%)$ and panuveitis $(546,12.53 \%)$. The etiological diagnosis of anterior uveitis, intermediate uveitis, posterior uveitis and panuveitis are shown in Figures 2,3,4 and 5 respectively and frequency distribution of all kinds of uveitis is shown in Table 2. 
Table 1. Frequency distribution according to sex, age, laterality and etiology

\begin{tabular}{|c|c|c|c|c|c|c|c|c|c|c|}
\hline & \multicolumn{2}{|c|}{$\mathbf{A U}$} & \multicolumn{2}{|c|}{ IU } & \multicolumn{2}{|c|}{ PU } & \multicolumn{2}{|c|}{ Pan } & \multicolumn{2}{|c|}{ Total } \\
\hline & $\mathrm{N}$ & $\%$ & $\mathrm{n}$ & $\%$ & $\mathrm{n}$ & $\%$ & $\mathrm{n}$ & $\%$ & $\mathrm{~N}$ & $\%$ \\
\hline \multicolumn{11}{|c|}{ Gender } \\
\hline Female & 1515 & 56.24 & 379 & 57 & 191 & 42.07 & 257 & 47.07 & 2342 & 53.73 \\
\hline Male & 1179 & 43.76 & 286 & 43 & 263 & 57.93 & 289 & 52.93 & 2017 & 46.27 \\
\hline \multicolumn{11}{|c|}{ Age } \\
\hline$<10$ & 58 & 2.15 & - & - & - & - & 1 & 0.18 & 59 & 1.35 \\
\hline $10-20$ & 296 & 10.98 & 73 & 10.98 & 129 & 28.41 & - & - & 498 & 11.42 \\
\hline $20-40$ & 1122 & 41.65 & 296 & 44.51 & 216 & 47.58 & 294 & 53.85 & 1928 & 44.23 \\
\hline $40-60$ & 864 & 32.07 & 296 & 44.51 & 88 & 19.38 & 83 & 15.2 & 1331 & 30.53 \\
\hline$>60$ & 354 & 13.14 & - & - & 21 & 4.63 & 168 & 30.77 & 543 & 12.46 \\
\hline \multicolumn{11}{|c|}{ Laterality } \\
\hline Unilateral & 1940 & 72.01 & 280 & 42.1 & 209 & 46.04 & 476 & 87.18 & 2905 & 66.64 \\
\hline Bilateral & 754 & 27.99 & 385 & 57.9 & 245 & 53.96 & 70 & 12.82 & 1454 & 33.36 \\
\hline \multicolumn{11}{|c|}{ Etiology } \\
\hline Infectious & 678 & 25.17 & 25 & 3.31 & 290 & 63.88 & 65 & 11.91 & 1058 & 24.27 \\
\hline Non-infectious & 370 & 13.73 & 13 & 1.95 & 94 & 20.7 & 67 & 12.27 & 544 & 12.48 \\
\hline Idiopathic & 1646 & 61.1 & 627 & 94.74 & 70 & 15.42 & 414 & 75.82 & 2757 & 63.25 \\
\hline Total & 2694 & $56.28 \%$ & 665 & $13.89 \%$ & 454 & $9.49 \%$ & 546 & $11.4 \%$ & 4359 & $100 \%$ \\
\hline
\end{tabular}

Table 2. Frequency distribution of etiology of all uveitis

\begin{tabular}{|c|c|c|c|c|c|c|c|c|c|c|}
\hline \multirow{2}{*}{ ETIOLOGY } & \multicolumn{2}{|c|}{$\mathbf{A U}$} & \multicolumn{2}{|c|}{ IU } & \multicolumn{2}{|c|}{ PU } & \multicolumn{2}{|c|}{ Pan } & \multicolumn{2}{|c|}{ Total } \\
\hline & $\mathrm{n}$ & $\%$ & $\mathrm{n}$ & $\%$ & $\mathrm{n}$ & $\%$ & $\mathrm{n}$ & $\%$ & $\mathrm{~N}$ & $\%$ \\
\hline \multicolumn{11}{|l|}{ Infectious causes } \\
\hline Herpetic & 608 & 22.57 & - & - & - & - & - & - & 608 & 13.95 \\
\hline Toxoplasmosis & - & - & - & - & 245 & 54 & 27 & 4.95 & 272 & 6.24 \\
\hline Tubercular uveitis & 61 & 2.26 & 20 & 3 & 7 & 1.54 & 13 & 2.38 & 101 & 2.32 \\
\hline Acute retinal necrosis & - & - & - & - & 28 & 6.17 & - & - & 28 & 0.64 \\
\hline Leprosy & 9 & 0.33 & 2 & 0.3 & - & - & - & - & 11 & 0.25 \\
\hline CMV & - & - & - & - & 7 & 1.54 & 2 & 0.37 & 9 & 0.21 \\
\hline SHAPU & - & - & - & - & - & - & 23 & 4.21 & 23 & 0.53 \\
\hline Scrub typhus & - & - & - & - & 3 & 0.66 & - & - & 3 & 0.07 \\
\hline Syphilis & - & - & 3 & 0.45 & - & - & - & - & 3 & 0.07 \\
\hline \multicolumn{11}{|c|}{ Specific ocular condition } \\
\hline $\begin{array}{l}\text { Posner Schlossman } \\
\text { Syndrome }\end{array}$ & 42 & 1.56 & - & - & - & - & - & - & 42 & 0.96 \\
\hline $\begin{array}{l}\text { Sympathetic } \\
\text { Ophthalmia }\end{array}$ & - & - & - & - & 4 & 0.88 & 10 & 1.83 & 14 & 0.32 \\
\hline Eales' Disease & - & - & - & - & 33 & 7.27 & 5 & 0.92 & 38 & 0.87 \\
\hline \multicolumn{11}{|c|}{ Associated Systemic Condition } \\
\hline Metabolic & 177 & 6.57 & - & - & - & - & - & - & 177 & 4.06 \\
\hline Rheumatoid arthritis & 62 & 2.3 & - & - & - & - & - & - & 62 & 1.42 \\
\hline Sarcoidosis & 5 & 0.19 & 9 & 1.35 & 13 & 2.86 & 26 & 4.76 & 53 & 1.22 \\
\hline $\begin{array}{l}\text { Vogt-Koyanagi- } \\
\text { Harada }\end{array}$ & - & - & - & - & 7 & 1.54 & 26 & 4.76 & 33 & 0.76 \\
\hline HLA-B27 related & 30 & 1.11 & - & - & - & - & - & - & 30 & 0.69 \\
\hline $\begin{array}{l}\text { Juvenile rheumatoid } \\
\text { arthritis }\end{array}$ & 28 & 1.03 & - & - & - & - & - & - & 28 & 0.64 \\
\hline SLE & - & - & - & - & 26 & 5.73 & - & - & 26 & 0.6 \\
\hline Behcet's disease & 1 & 0.04 & 3 & 0.45 & 11 & 2.42 & - & - & 15 & 0.34 \\
\hline Gout & 12 & 0.45 & - & - & - & - & - & - & 12 & 0.28 \\
\hline Psoriasis & 9 & 0.33 & - & - & - & - & - & - & 9 & 0.21 \\
\hline Tuberous Sclerosis & - & - & 1 & 0.15 & - & - & - & - & 1 & 0.02 \\
\hline $\begin{array}{l}\text { Benign intracranial } \\
\text { tension }\end{array}$ & 1 & 0.04 & & & & & & & 1 & 0.02 \\
\hline TINU & 1 & 0.04 & & & & & & & 1 & 0.02 \\
\hline \multicolumn{11}{|l|}{ Masquerade syndrome } \\
\hline Small bowel GIST & 1 & 0.04 & - & - & - & - & - & - & 1 & 0.02 \\
\hline $\begin{array}{l}\text { Langerhan's cell } \\
\text { histiocytosis }\end{array}$ & 1 & 0.04 & - & - & - & - & - & - & 1 & 0.02 \\
\hline Total known etiology & 1048 & 38.9 & 38 & 5.71 & 384 & 84.58 & 132 & 24.18 & 1602 & 36.75 \\
\hline Idiopathic & 1646 & 61.1 & 627 & 94.29 & 70 & 15.42 & 414 & 75.82 & 2757 & 63.25 \\
\hline Total & 2694 & 100 & 665 & 100 & 454 & 100 & 546 & 100 & 4359 & 100 \\
\hline
\end{tabular}




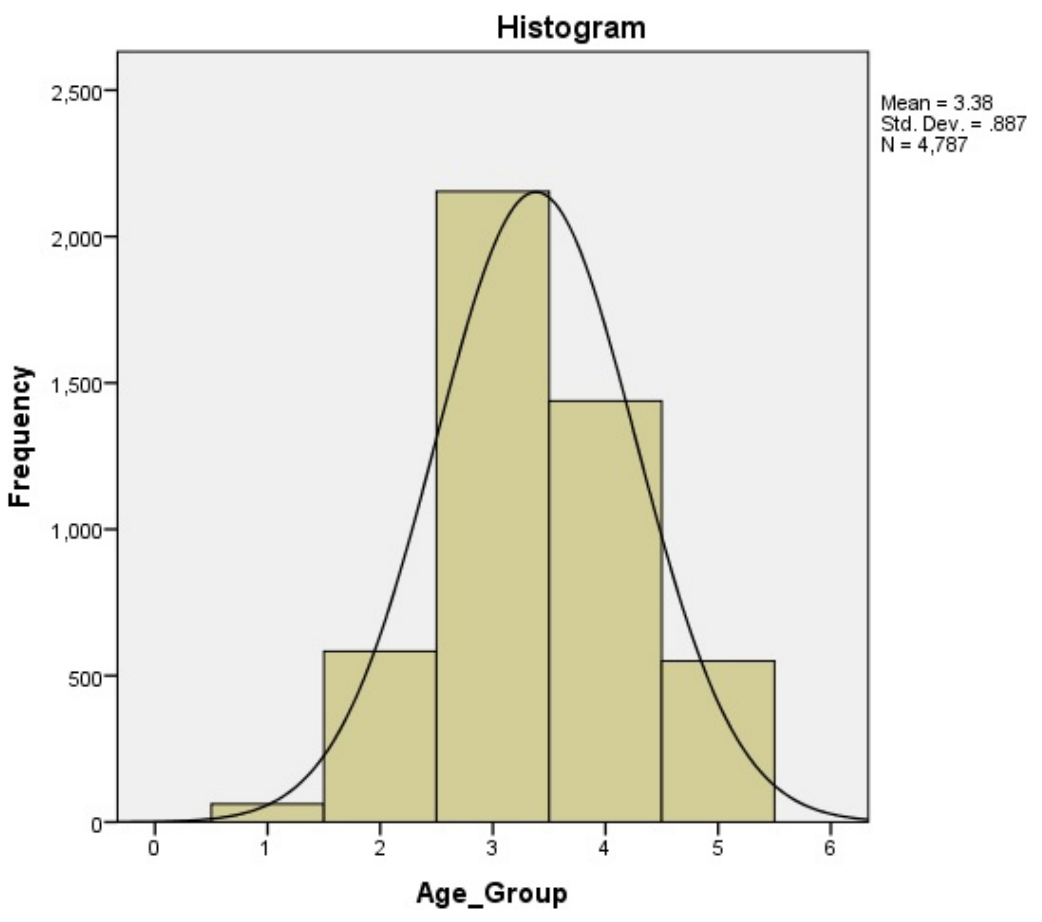

Figure 1. Age distribution following the normal distribution curve

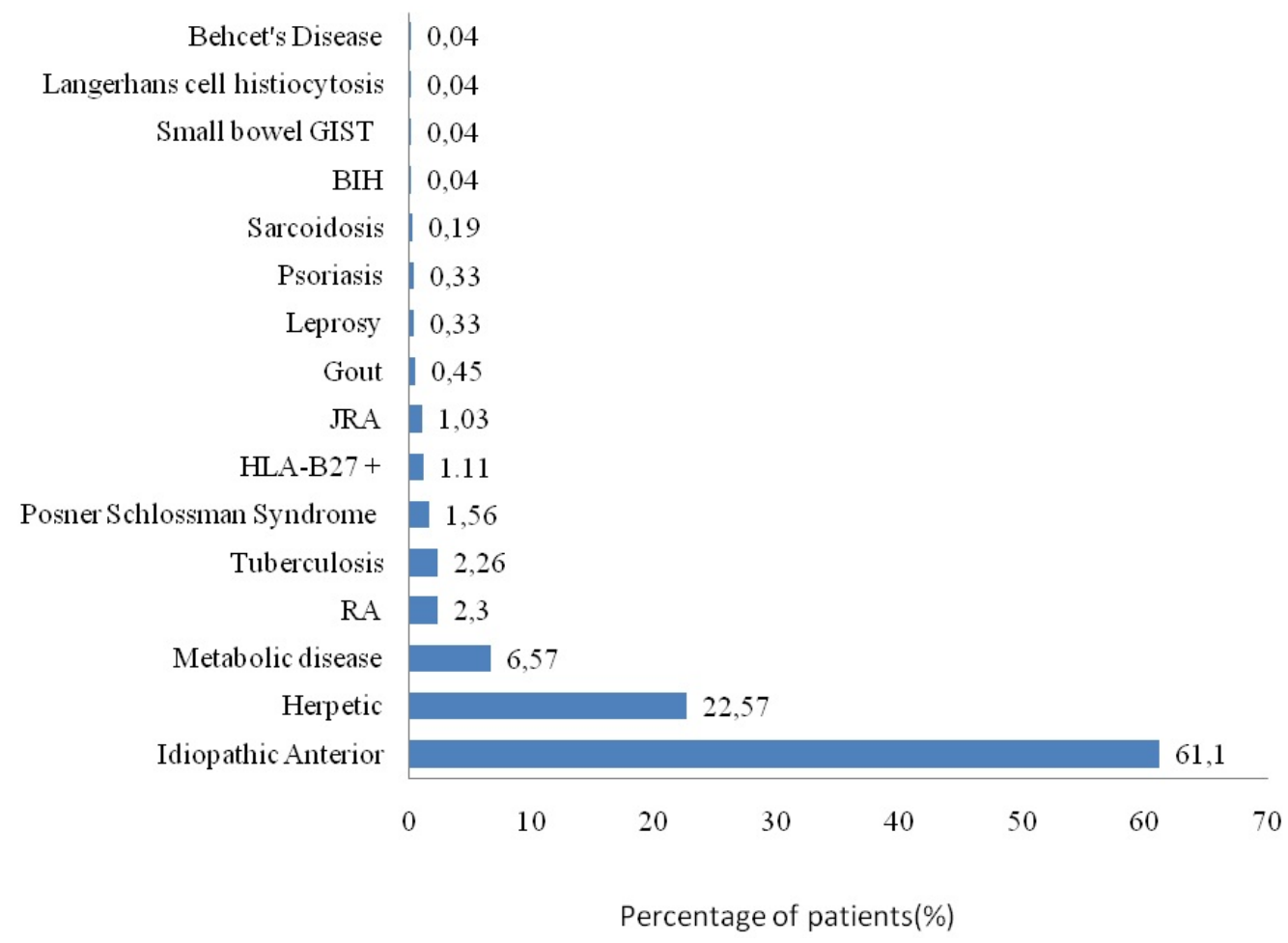

Figure 2. Distribution of various etiology of anterior uveitis

Among 4359 patients, specific etiology could be established in 1602 (36.75\%) patients whereas 2757 (63.25\%) cases remained idiopathic. Among those cases, where etiology could be established, the infectious cause was seen in $24.27 \%$ cases whereas non-infectious cause in $12.48 \%$ cases. Among the infectious cause, herpetic uveitis ranked the first $(608,13.95 \%)$, followed by toxoplasmosis $(272,6.24 \%)$ (Figure 6A), tuberculosis (101, 2.32\%) (Figure 6B), acute retinal necrosis (28 cases,
0.64\%), SHAPU (23 cases, $0.53 \%$ ) (Figure 7), leprosy (11 case, $0.25 \%$ ), CMV (9 cases, $0.21 \%$ ), scrub typhus ( 3 cases, $0.07 \%$ ) and syphilis (3 cases, $0.07 \%)$.

Specific ocular conditions like Posner-Schlossmann syndrome (42, $0.96 \%)$, Eales' disease $(38,0.87 \%)$ and sympathetic ophthalmia (14, $0.32 \%)$ were diagnosed. 


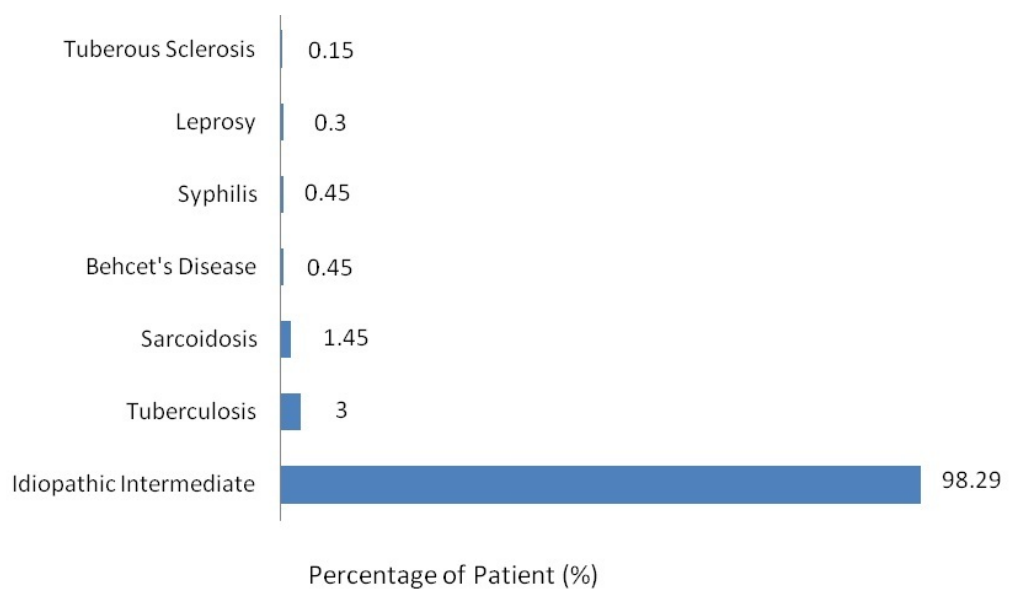

Figure 3. Distribution of various etiology of intermediate uveitis

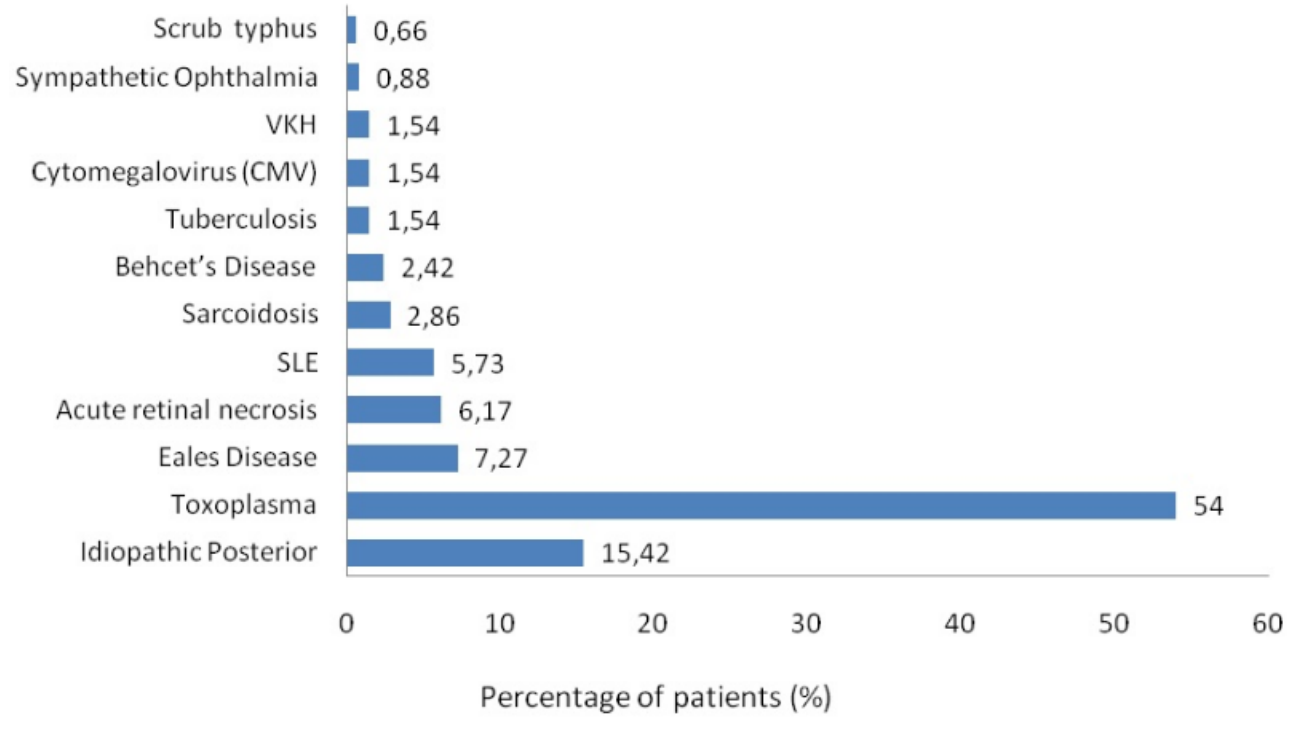

Figure 4. Distribution of various etiology of posterior uveitis

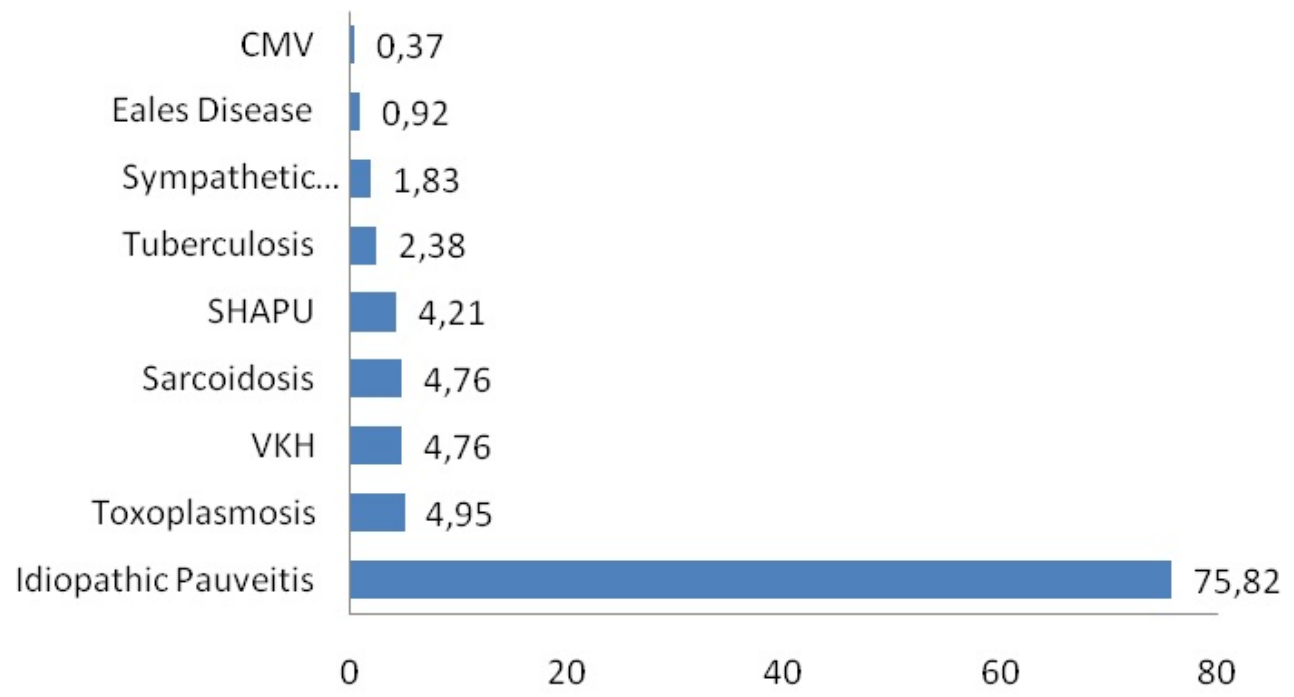

Percentage of patients (\%)

Figure 5. Distribution of various etiology of panuveitis 
Likewise, various systemic disorders were also seen to be associated with uveitis like metabolic disorder $(177,4.06 \%)$, rheumatoid arthritis $(62,1.42 \%)$, sarcoidosis $(53,1.22 \%)$, HLA-B27 related diseases (30, $0.69 \%)$, Vogt-Koyanagi-Harada $(33,0.76 \%)$, and juvenile rheumatoid arthritis $(28,0.64 \%)$. We also found uveitis in rare diseases liketuberous sclerosis, small bowel GIST, Langerhan's cell histiocytosis and Idiopathic intracranial hypertension $(1,0.02 \%$ each). Tuberous sclerosis was associated with intermediate uveitis whereas rest was associated with anterior uveitis.

In our study, 3677 eyes (63.26\%) had vision between $6 / 6$ to $6 / 18$ whereas 661 eyes $(11.37 \%)$ had vision $<3 / 60$. Table 3 shows vision among various forms. Complications were documented in $37.23 \%$
(2164 eyes) among our study population. The most frequently encountered complication was macular edema $(863,14.85 \%)$, followed by complicated cataract (581 eyes, 10\%), ocular hypertension (523 eyes, 9\%) and disc edema (197 eyes, 3.39\%) as shown in Table 4.

\section{Discussion}

Uveitis refers to approximately 25 different disorders, all characterized by the presence of intraocular inflammation [15]. In this study, 5813 eyes of 4359 patients meeting the inclusion criteria were included. There was a very slight female preponderance, however, the previous report from Nepal showed equal distribution [16-18]. Some reports from South India have also suggested this trend with an increase
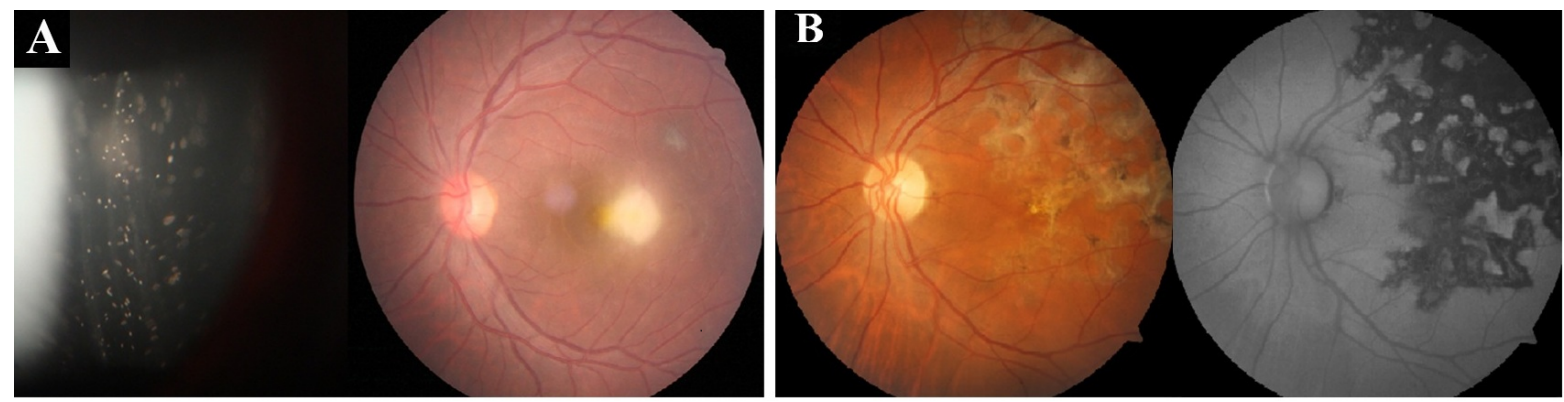

Figure 6. Clinical photographs of patient with toxoplamosis (A) and with Tubercular serpiginous choroiditis(B)

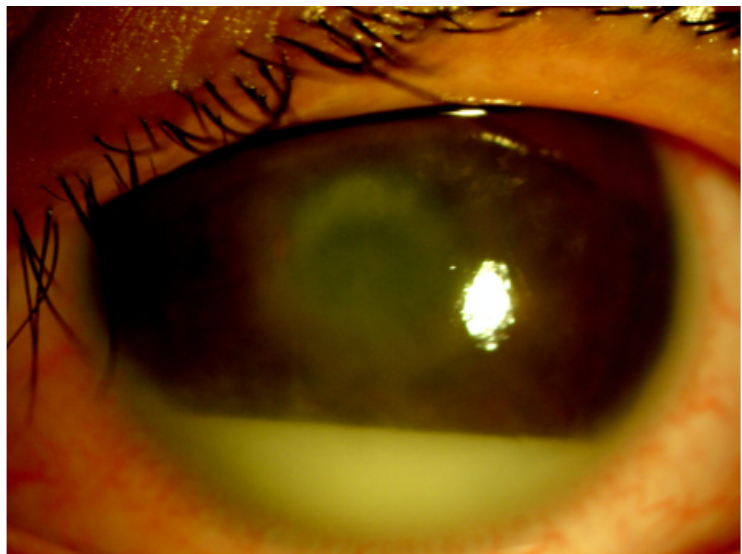

Figure 7. Seasonal Hyperacute Panuveitis (SHAPU) case with dense anterior chamber reaction with hypopyon and whitish pupillary reflex

Table 3. Frequency distribution of visual acuity in various types of uveitis

\begin{tabular}{|c|c|c|c|c|c|c|c|c|c|c|}
\hline \multirow{2}{*}{ Visual acuity } & \multicolumn{2}{|c|}{$\mathbf{A U}$} & \multicolumn{2}{|c|}{ IU } & \multicolumn{2}{|c|}{$\mathbf{P U}$} & \multicolumn{2}{|c|}{ Pan } & \multicolumn{2}{|c|}{ Total } \\
\hline & $\mathrm{n}$ & $\%$ & $\mathrm{n}$ & $\%$ & $\mathrm{n}$ & $\%$ & $\mathrm{n}$ & $\%$ & $\mathrm{n}$ & $\%$ \\
\hline 6/6-6/18 & 2608 & 75.64 & 460 & 43.81 & 349 & 49.93 & 260 & 42.21 & 3677 & 63.26 \\
\hline $6 / 24-6 / 60$ & 508 & 14.73 & 391 & 37.24 & 242 & 34.62 & 81 & 13.15 & 1222 & 21.02 \\
\hline $5 / 60-3 / 60$ & 89 & 2.58 & 92 & 8.76 & 27 & 3.86 & 45 & 7.31 & 253 & 4.35 \\
\hline$<\mathbf{3 / 6 0}$ & 243 & 7.05 & 107 & 10.19 & 81 & 11.59 & 230 & 37.34 & 661 & 11.37 \\
\hline Total eyes & 3448 & 100 & 1050 & 100 & 699 & 100 & 616 & 100 & 5813 & 100 \\
\hline
\end{tabular}

Table 4. Frequency distribution of common complications

\begin{tabular}{|c|c|}
\hline Complications & No. of eyes (\%) \\
\hline Macular edema & $863(14.85 \%)$ \\
\hline Complicated cataract & $581(10 \%)$ \\
\hline Ocular hypertension & $523(9 \%)$ \\
\hline Disc edema & $197(3.39 \%)$ \\
\hline Total eyes with complications & $2164(37.23)$ \\
\hline
\end{tabular}


in female preponderance from $36 \%$ to $44 \%$ [19]. But, the scenario on gender distribution is fluctuating in a different part of the world.

The mean age of presentation in this study was $37.91 \pm 17.2$ years (Range 38 days to 84 years). A 38 - day baby boy had SHAPU and is the youngest reported case of SHAPU till date [20]. However, most of the uveitis patients were in their 2nd-4th decade i.e. working age group. Ocular morbidity in these people at their heights of active age is a direct loss to the socio-economic status of the family and country. This scenario holds true for our neighboring countries like India and China too $[18,21,22]$.

The majority of our patients had unilateral disease (66.64\%), which is similar to most of the literature from both developed and developing the world. Unilateral uveitis appeared to be either equal or more common than bilateral except in comparison to countries with a higher frequency of sarcoidosis and Behçet syndrome, which commonly causes bilateral disease [10-12,19-22,23]. Piergiorgio Neri et al reported predominant bilateral involvement (63.2\%) in their study and highlighted that this could probably be due to more number of chronic uveitis compared to acute cases [24].

In our study, anterior uveitis was the most common form accounting for $61.8 \%$, followed by intermediate uveitis (15.26\%), panuveitis (12.53\%), and posterior uveitis (10.42\%). Indian studies have also showed anterior uveitis as common form uveitis [14,25,26]. But reports from Saudi Arabia and Iraq showed a different trend where the most common anatomic diagnosis was panuveitis and posterior uveitis $[27,28]$. Panuveitis was also reported to be common in Japan perhaps because of a higher prevalence of Vogt-Koyanagi-Harada (VKH) disease, Behcet's syndrome and sarcoidosis which often presents with both anterior and posterior inflammation [29].

Nepal, being an agricultural and developing country, there is a lack of the availability of the newer technology and sophisticated investigative tools like Real-time Polymerase chain reaction analysis machine. Hence, a definite diagnosis could not be established in a large number of infective cases and possibly those fell under the category of idiopathic diseases. Even in developed countries, for a sizeable proportion of patients, the cause of uveitis remains unknown despite the appropriate investigation, regardless of age, gender or anatomical location. Previous surveys have suggested that the cause of uveitis remains unknown in approximately $30-60 \%$ of patient [23]. Similarly, in our study, with the currently available investigative facilities, etiology could be identified in $36.75 \%$ thereby $63.25 \%$ of cases remained idiopathic. This is similar to the study from Eastern India where specific diagnosis could be established in $31.06 \%$ [30]. Likewise, in the report from the Apex Institute for Eye Care in India by Venkatesh et al etiology could be made in $23 \%$ cases only [31]. Das et al too reported that the etiology remained undetermined in the majority of the cases (58.7\%) [32]. In general, anterior and intermediate uveitis is more often idiopathic than are posterior and diffuse forms of inflammation [33]. The findings from our study also suggested that most of the intermediate uveitis were idiopathic as compared to other anatomical variants.

In our study, infectious uveitis (24.27\%) was more common than non-infectious uveitis $(12.48 \%)$ which agrees with other reports from Nepal and India [16,33]. Among infectious diseases, herpetic uveitis (13.95\%), toxoplasmosis (6.24\%) and tuberculosis (2.32\%) were the common cause. In a case of ocular toxoplasmosis, we could even isolate both tachyzoites and bradyzoites from the vitreous sample [34].

The percentage of infectious causes in our series $(24.27 \%)$ is between the values described in developed countries (11-21\%) and those of developing countries (30-50\%) [16,17]. In a study from India, the predominant infectious uveitis include leptospirosis (9.7\%), tuberculosis (5.6\%) and herpetic disorders (4.9\%) [33]. Venkataraman et al \& Rathinam et al showed tuberculosis, toxoplasmosis and herpetic uveitis as common infectious diseases which matches with a report from Saudi Arabia and Chile [21,27,35]. Likewise, studies from North Africa and Saudi Arabia also show herpetic uveitis as the most common infectious uveitis $[26,36]$.

Among, noninfectious diseases, RA and sarcoidosis were common systemic disorders. In the previous report from Nepal, ankylosing spondylitis, VKH, and sarcoidosis were common [16,17]. Likewise, VKH, HLAB27 related disorder, and diabetic associated uveitis were common in Chile 37 and India [21,33].

In our study, there were 12 cases (0.28\%) cases of gout. Early in 1968, Killen et al reported a case who had uveitis and arthritis who did not improve on the topical and oral steroid but had significant improvement after treatment of gout. W. Lang (1913) and B. T. Lang (1913) estimated gout as the causative factor of uveitis in 3.5\% of cases, but Gilbert (1930) gave the incidence as only $1 \%$. Ashton and Duke-Elder (1962) stated that urate crystals might be deposited in almost any tissue including the eye. Meunzler and Gerber (1963) too described a case a uveitis who responded to treatment for gout and topical treatment to the eyes [37].

We also found a case of Langerhans cell histiocytosis presenting with bilateral non-granulomatous hemorrhagic anterior uveitis with exudative retinal detachment and secondary glaucoma [38]. A case of Langerhans cell histiocytosis presenting as anterior uveitis and iris nodules has been reported by Tsai et al in 2005 [39].

We also found rare diseases like BIH (Benign Intracranial Hypertension), tuberous sclerosis and small bowel GIST presenting as uveitis. This could be accidental yet interesting finding, hence further studies are mandatory for establishing these diseases as etiology of uveitis.

Etiology could be found in $36.75 \%$ of cases of anterior uveitis in which herpetic uveitis ranked the first, comparable with other reports followed by tuberculosis and leprosy $[16,26,33,40]$. Viral and tubercular infections are commoner in a developing country like ours.

Likewise, metabolic disorder and rheumatoid arthritis were common systemic disorder identified. In our study there were 177 patient (3.69\%) of anterior uveitis who had diabetes included under metabolic disorder. DM associated uveitis has been reported as rare disease and its pathophysiology has been attributed to immunological causes [41-43]. It is not certain whether our patients with medical history of DM accidentally suffered from idiopathic uveitis or if DM was the direct cause of uveitis Glycaemic improvements may prevent recurrence [44]. Association between poorly controlled DM and anterior uveitis was seen from report Japan [45].

Posner-Schlossmann syndrome was seen in $0.96 \%$ of cases presenting as anterior uveitis comparable with a report by Rathinam et al. [33].

In our study, maximum cases (94.29\%) of intermediate uveitis remained idiopathic. However, intermediate uveitis was the manifesting feature of three of our syphilis case. Other associated conditions were tuberculosis, sarcoidosis, and leprosy which has also been reported in various other studies $[17,19,33,46,47]$. None of the patients of the intermediate uveitis group were diagnosed with multiple sclerosis or lymphoma. This observation has to be considered carefully because we did not ask for a neurological consultation in all cases; therefore, some 
cases may have been missed because lost follow-up or failure to identify its early clinical manifestations.

Among posterior uveitis, toxoplasmosis (54\%) was the most common etiology similar to other studies $[16,26,35,36,40,48,49]$. In reports from Singapore, Dengue was the commonest followed by toxoplasmosis [50,51].

Toxoplasmosis, sarcoidosis, and VKH were common among panuveitis which is comparable with other studies $[19,52,53]$. SHAPU was the commonest type of panuveitis among Nepalese children followed by toxoplasmosis. SHAPU outbreak has been regularly noted in Nepal, in odd years during post-monsoon season prevalently among children since 1975 and leads to loss of sight and cosmetic disfigurement within a week $[54,55]$. In the literature, the youngest reported SHAPU case was a 9-months-child 55 but we could report SHAPU in a 38-daybaby during 2017 outbreak [56]. Oscillating between non-infective and infective origin, aetiopathogenesis of SHAPU is yet not well understood. Hence, there is an urgent need to perform whole genomic sequencing and cytokines biomarkers analysis of the aspirated ocular fluid samples to solve unsolved 43 years long mystery of its etiology. White moth has been established as the Risk factor during 2017 SHAPU outbreak [57,58]. It still remains unknown how do moths cause this disease? Is it an infective etiology or an immunological phenomenon? Which variant of moth, which part of life cycle of moths, which toxins do these moth carry causing such fulminant reaction etc need to be answered in the future studies.

Several Asian studies found panuveitis to be the most common form, with Behçet disease being one of the top etiologies $[5,59,60]$. However, this was not true in our scenario.We found that tuberculosis is not an uncommon cause of uveitis in our population and it can affect any or all the anatomical parts of the eye and its adnexa that is in agreement with the previous study. The World Health Organization estimates that one-third of the world's population is currently infected with tuberculosis, with 9 million new cases occurring annually, leading to 3 million deaths per year (WHO Report, 2007) [61]. Recent data shows 80,000 people have tuberculosis in Nepal, with more than 40,000 new cases arising every year [62]. Studies from various parts of the world have shown tuberculosis as an important infectious cause for uveitis $[6,22,33,40,63,64]$. As reported in study from Poland, patients from rural areas had significantly higher frequency of infectious uveitis which may due to significant human contact with animals and contaminated soil which may be in our scenario too [65]. A more recent publication from Japan also showed a marked increased frequency of systemic as well as ocular tuberculosis [29].

A wide variety of structural complications including cataract, glaucoma, macular edema, epiretinal membrane inflammation, and neovascularization, both retinal and choroidal can be associated with uveitis which may result in visual impairment [66-68]. The most frequently encountered complications by us was macular edema followed by cataract.

The strength of our study is that it presents the large scale data from 5813 eyes of 4359 patients over 5 years, and the fact that our eye center is the part of the multispeciality largest tertiary referral general hospital of Nepal. So these data could be the representation of the nationwide data. However, limitations include possible selection bias as we are a tertiary institution, so there may be a larger proportion of more severe uveitis and less severe forms were not referred. Another limitation is the lack of newer diagnostic modalities like PCR, OCTA which could have helped to reduce the number of idiopathic uveitis cases.

\section{Conclusion}

In conclusion, we have described the clinical profile of uveitis in a large sample in Nepal and we reported the demographical, epidemiological and clinical scenario of uveitis among Nepalese population. Unilateral cases are prevalent than bilateral and people of 2nd-4th decade of their lives are commonly affected. Toxoplasmosis and tuberculosis are common cause of uveitis in our part of world. SHAPU remains the commonest cause of pediatric panuveitis in Nepal.

\section{Declaration of interest}

The author declares no potential conflicts of interest with respect to the authorship, and/or publication of this article.

A. Ethics approval and consent to participate: Ethical Approval for the study was obtained from the Institutional Review Board of Institute of Medicine and consent from participants were obtained.

B. Consent for publication: Was obtained from the Institutional Review Board and the patients.

C. Availability of data and material: Please contact author for data requests.

\section{Funding: None}

E. Authors' contributions: RKS and AK were involved in the study design. NSG, RKS, AKS, DNS were involved in the disease management and patient care. RKS, AK, NSG were involved in manuscript writing and result analysis. AKS and DNS contributed in manuscript critical review. All authors read and approved the final manuscript. All contributors meet the criteria for authorship.

F. Acknowledgements: We would like to acknowledge the medical record unit of BPKLCOS for helping us with the data. We are also grateful to Mr Suresh Sharma for the photography.

G. Competing Interests: The authors declare that they have no competing interests. The authors alone are responsible for the content and writing of the paper.

\section{References}

1. Nussenblatt RB (1990) The natural history of uveitis. Int ophthalmol 14: 303-308. [Crossref]

2. Darrell R, Wagener H, Kurland L (1962) Epidemiology of uveitis:incidence and prevalence in a small urban community. Arch Ophthalmol 68: 502-514. [Crossref]

3. Wakefield D, Chang JH (2005) Epidemiology of uveitis. Int Ophthalmol Clin 45: 1-13.

4. Gritz DC, Wong IG (2004) Incidence and prevalence of uveitis in Northern California The Northern California epidemiology of uveitis study. Ophthalmology 111: 491-500. [Crossref]

5. Chen EJ, Bin Ismail MA, Mi H, Ho SL, Lim WK, et al. (2018) Ocular Autoimmune Systemic Inflammatory Infectious Study (OASIS) - Report 1: Epidemiology and Classification. Ocul Immunol Inflamm 26: 732-746. [Crossref]

6. Rothova A, Buitenhuis HJ, Meenken C, Brinkman CJ, Linssen A, et al. (1992) Uveitis and systemic disease. Br J Ophthalmol 76: 137-141. [Crossref]

7. Deschenes J, Murray PI, Rao NA, Nussenblatt RB (2008) International Uveitis Study Group (IUSG): clinical classification of uveitis. Ocul Immunol Inflamm 16: 1-2.

8. Jabs DA, Nussenblatt RB, Rosenbaum JT, SUN Working Group (2005) Standardization of uveitis nomenclature for reporting clinical data. Results of the First International Workshop. Am J Ophthalmol 140: 509-516.

9. Elizabeth J Chen, Bin Ismail MA, Mi H, Ho SL, Lim WK, et al. (2016): Ocular Autoimmune Systemic Inflammatory Infectious Study (OASIS) - Report 1: Epidemiology and Classification. Ocul Immunol Inflamm 26: 732-746. [Crossref] 
10. Herbort CP, Rao NA, Mochizuki M (2009) International criteria for the diagnosis of ocular sarcoidosis: results of the first International Workshop On Ocular Sarcoidosis (IWOS). Ocul Immunol Inflamm 17: 160-169. [Crossref]

11. International Study Group for Behcet's Disease (1990) Criteria for diagnosis of Behcet's disease. Lancet 335: 1078-1080.

12. Read RW, Holland GN, Rao NA, Tabbara KF, Ohno S, et al. (2001) Revised diagnostic criteria for Vogt-Koyanagi-Harada disease: report of an international commitee on nomenclature. Am J Ophthalmol 131: 647-652. [Crossref]

13. Upadhyay M, Kharel Sitaula R, Shrestha B (2018) Seasonal Hyperacute Panuveitis in Nepal: A Review over 40 Years of Surveillance. Ocul Immunol Inflamm 2018: 1-9. [Crossref]

14. Anadi Khatri, Ranju Kharel, Sagun Narayan Joshi, Pratap Karki, Ranjit Sah (2017) SHAPU- Seasonal Hyperacute Pan-Uveitis. Am Acad Ophthalmol 22: 14458

15. Jabs DA (2008) Epidemiology of uveitis. Ophthalmic Epidemiol 15: 283-284.

16. Manandhar A (2017) Patterns of Uveitis and Scleritis in Nepal: A Tertiary Referra Center Study. Ocul Immunol Inflamm 2017: 25. [Crossref]

17. Shrestha JB, Shah DN (2017) Systemic association of uveitis in Nepalese population. JChitwan Med College 7: 19.

18. Shrestha S, Thapa M, Shah DN (2014) Pattern of intraocular pressure fluctuation in uveitic eyes treated with corticosteroids. Ocul Immunol Inflamm 22: 110-115. [Crossref]

19. Biswas J, Kharel (Sitaula) R, Multani P (2018) Changing uveitis patterns in South India- Comparison between two decades. Indian J Ophthalmol 66: 524-527. [Crossref]

20. Ranju K, Joshi SN, Sharma AK, Upadhyay MP (2018) Youngest Reported Case of SHAPU. XIV Biennial SAARC Academy of Ophthalmology (SAO) Conference 2018 in Conjunction with XXth Nepal Ophthalmic Society Annual Meeting. Kathmandu, Nepal.

21. Venkataraman A, Rathinam S (2008) A pre- and post-treatment evaluation of vision -related quality of life in uveitis. Indian J Ophthalmol 56: 307-312.

22. Yang P, Zhang Z, Zhou H, Li B, Huang X, et al. (2005) Clinical patterns and characteristics of uveitis in a tertiary center for uveitis in China. Curr Eye Res 30: 943-948. [Crossref]

23. Rathinam SR, Namperumalsamy P (2007) Global variation and pattern changes in epidemiology of uveitis. Indian J Ophthalmol 55: 173-183. [Crossref]

24. Neri P, Azuara-Blanco A, Forrester JV (2004) Incidence of glaucoma in patients with uveitis. J Glaucoma 13: 461-465. [Crossref]

25. James DG, Friedmann AI, Graham E (1976) Uveitis. A series of 368 patients. $B r J$ Ophthalmol 96: 108-112.

26. Khairallah M, Yahia SB, Ladjimi A, Messaoud R, Zaouali S, et al. (2007) Pattern of uveitis in a referral centre in Tunisia, North Africa. Eye (London, England) 21: 33-39.

27. Al-Mezaine HS, Kangave D, Abu El-Asrar AM (2010) Patterns of uveitis in patients admitted to a University Hospital in Riyadh, Saudi Arabia. Ocul Immunol Inflamm 18: 424-431. [Crossref]

28. Al-Shakarchi FI (2014) Pattern of uveitis at a referral center in Iraq. Middle East Afr $J$ Ophthalmol 21: 291-295. [Crossref]

29. Kotake S, Furudate N, Sasamoto Y, Yoshikawa K, Goda C, et al. (1996) Characteristics of endogenous uveitis in Hokkaido, Japan. Graefe's archive for clinical and experimental ophthalmology. Archiv fur klinische und experimentelle Ophthalmologie 234: 599-603.

30. Das S, Pathak S, Chatterjee PK, Majumder NK (2011) Demographic, morphologic and aetiological profile of uveitis patients presenting in a tertiary eye hospital in Eastern India. J Indian Med Assoc 109: 794-796. [Crossref]

31. Venkatesh P, Gogia V, Shah B, Gupta S, Sagar P, et al. (2015) Patterns of uveitis at the Apex Institute for Eye Care in India: Results from a prospectively enrolled patient data base (2011-2013). Int ophthalmol 36: 365-72. [Crossref]

32. Das D, Biswas J, Ganesh SK (1995) Pattern of uveitis in a referral uveitis clinic in India. Indian J Ophthalmol 43:117-121.

33. McCannel CA, Holland GN, Helm CJ, Cornell PJ, Winston JV, et al. (1996) Causes of uveitis in the general practice of ophthalmology. UCLA Community-Based Uveitis Study Group. Am J Ophthalmol 121: 35-46.

34. Kharel(Sitaula) R, Joshi SN, Sah R, Khadka S, Khatri(KC) A, et al. (2018) Toxoplasma gondii bradyzoites and tachyzoites isolation from vitreous of atypical necrotizing retinitis. J Ophthalmic Inflamm Infect 8: 8. [Crossref]
35. Liberman P, Gauro F, Berger O, Urzua CA (2015) Causes of Uveitis in a Tertiary Center in Chile: A Cross-sectional Retrospective Review. Ocul Immunol Inflamm 23: 339-345. [Crossref]

36. Hamade IH, Elkum N, Tabbara KF (2009) Causes of uveitis at a referral center in Saudi Arabia. Ocul Immunol Inflamm 17:11-16.

37. Killen BU (1968) Gout and uveitis: Report of a case. Br J Ophthalmol 52: 710-712.

38. Sitaula RK, Khatri A (2018) Langerhans cell histiocytosis with hemorrhagic uveitis and exudative retinal detachment. Int Med Case Rep J 11: 65-68. [Crossref]

39. Tsai JH, Galaydh F, Ching SS (2005) Anterior uveitis and iris nodules that are associated with Langerhans cell histiocytosis. Am J Ophthalmol 140: 1143-1145.

40. Mercanti A, Parolini B, Bonora A, Lequaglie Q, Tomazzoli L (2001) Epidemiology of endogenous uveitis in north-eastern Italy. Analysis of 655 new cases. Acta Ophthalmol Scand 79: 64-68.

41. Murray PI, Russell-Eggitt IM (1991) An unusual presentation of diabetes mellitus Metab Pediatr Syst Ophthalmol 14: 16-17.

42. Rothova A, Meenken C, Michels RP, Kijlstra A (1988) Uveitis and diabetes mellitus. Am J Ophthalmol 106:17-20. [Crossref]

43. Castagna I, Fama` F, Salmeri G (1995) Anterior uveitis and diabetes mellitus: immunological study. Ophthalmologica 209: 53-55.

44. Ansari AS, De Lusignan S, Hinton W (2018) Glycemic control is an important modifiable risk factor for uveitis in patients with diabetes. $J$ Diab Complicat 32: 602608

45. Watanabe T, Keino H, Nakayama K (2019) Clinical features of patients with diabetic anterior uveitis Br J Ophthalmol 103: 78-82.

46. Das D, Bhattacharjee H, Bhattacharyya PK, Jain L, Panicker MJ, et al. (2009) Pattern of uveitis in North East India: a tertiary eye care center study. Indian J Ophthalmol 57: 144-146. [Crossref]

47. Malla OK, Karki DB, Byanju RN, Shrestha S (2004) Intermediate uveitis: a hospita based study. Kathmandu Univ Med J 2: 354-349.

48. Kianersi F, Mohammadi Z, Ghanbari H, Ghoreyshi SM, Karimzadeh H, et al. (2015) Clinical Patterns of Uveitis in an Iranian Tertiary Eye-care Center. Ocul Immunol Inflamm 23: 278-282. [Crossref]

49. Miettinen R (1977) Incidence of uveitis in northern Finland. Acta Ophthalmol (Copenh) $55: 252-260$.

50. Lee JH, Mi H, Lim R, Ho SL, Lim WK, et al. (2017) Ocular Autoimmune Systemic Inflammatory Infectious Study - Report 3: Posterior and Panuveitis. Ocul Immunol Inflamm 9: 1-10.

51. Mi H, Ho SL, Lim WK, Wong EP, Teoh SC (2015) Trends in Patterns of Posterior Uveitis and Panuveitis in a Tertiary Institution in Singapore. Ocul Immunol Inflamm 23: 329-338.

52. Singh R, Gupta V, Gupta A (2004) Pattern of uveitis in a referral eye clinic in north India. Indian J Ophthalmol 52: 121-125. [Crossref]

53. Biswas J, Narain S, Das D (1997) Patterns of uveitis in a referral uveitis clinic in India. Int Ophthalmol 20: 223-228.

54. Upadhayay M, Rai N and Ogg J (1984) Seasonal Hyper Acute Panuveitis in Saarikm (ed): Uveitis update. Excerpta Medica, Amsterdam.

55. Manandhar A (2011) Seasonal hyperacute panuveitis: an update. Curr Opin Ophthalmol 22: 496-501. [Crossref]

56. Ranju Kharel (Sitaula), Pratap Karki, Sagun Narayan Joshi, Ananda K Sharma, Madan P Upadhyay (2018) A case report of the youngest child with SHAPU. Poster Session Presented at at XIV Biennial SAARC Academy of Ophthalmology (SAO) Conference 2018 in Conjunction with XXth Nepal Ophthalmic Society Annual Meeting. June 21st -24th, 2018 Kathmandu, Nepal.

57. Upadhyay MMA, Kharel Sitaula R, Joshi N S (2017) Orientation \& Sensitization of Health workers \& Case Control Study Of Seasonal Hyperacute Panuveitis (SHAPU) In: Organisation ArcutsoWH, (ed.). BP Eye Foundation (BPEF), Kathmandu, Nepal, pp. 1-81.

58. Upadhyay MMA, Kharel Sitaula R, Joshi N S (2017) Risk Factors of Seasona Hyperacute Panuveitis. A research conducted under the support of World Health Organisation Countryside office Nepal, 2017-2018 (under process of publishment).

59. Wakabayashi T, Morimura Y, Miyamoto Y (2003) Changing patterns of intraocular inflammatory disease in Japan. Ocul Immunol Inflamm 11: 277-286. [Crossref] 
60. Sittivarakul W, Bhurayanontachai P, Ratanasukon M (2013) Pattern of uveitis in a university-based referral center in southern Thailand. Ocul Immunol Inflamm 21: 5360. [Crossref]

61. Sharma A, Thapa B, Lavaju P (2009) Ocular tuberculosis: an update. Nepal $J$ Ophthalmol 3: 52-67.

62. Annual report of National Tuberculosis Programme, Nepal, 2012-13.

63. Merrill PT, Kim J, Cox TA, Betor CC, McCallum RM, et al. (1997) Uveitis in the southeastern United States. Curr Eye Res 16: 865-74. [Crossref]

64. Smit RL, Baarsma GS, de Vries J (1993) Classification of 750 consecutive uveitis patients in the Rotterdam Eye Hospital. Int Ophthalmol 17: 71-76. [Crossref]
65. Biziorek B, Mackiewicz J, Zagorski Z, Krwawicz L, Haszcz D (2001) Etiology of uveitis in rural and urban areas of mid-eastern Poland. Ann Agric Environ Med 8: 241243.

66. Prieto-del-Cura M, Gonzalez-Guijarro J (2009) Complications of uveitis: prevalence and risk factors in a series of 398 cases. Arch Soc Esp Oftalmol 84: 523-528. [Crossref]

67. Jones NP (2015) The Manchester Uveitis Clinic: The first 3000 patients, 2: Uveitis Manifestations, Complications, Medical and Surgical Management. Ocul Immunol Inflamm 23: 127-34. [Crossref]

68. Rothova A, Suttorp-van Schulten MS, Frits Treffers W, Kijlstra A (1996) Causes and frequency of blindness in patients with intraocular inflammatory disease. $\mathrm{Br} J$ Ophthalmol 80: 332-336. [Crossref]

Copyright: @2019 Kharel R. This is an open-access article distributed under the terms of the Creative Commons Attribution License, which permits unrestricted use, distribution, and reproduction in any medium, provided the original author and source are credited. 